\title{
HUBUNGAN TINGKAT PENGETAHUAN TENTANG HIPERTENSI DENGAN SIKAP DALAM PENCEGAHAN KOMPLIKASI HIPERTENSI PADA LANSIA PESERTA PROLANIS UPT PUSKESMAS JENAWI KARANGANYAR
}

\section{Relationship Of The Level Of Knowledge About Hypertension With Attitude In The Prevention Of Complication Of Hypertension In Elderly Participants PROLANIS Public Health Center Jenawi Karanganyar}

\author{
Mujiran $^{1)}$, Setiyawan'), Noerma Shovie Rizqie ${ }^{3)}$ \\ ${ }^{*}$ Program Studi Sarjana Keperawatan STIKes Kusuma Husada Surakarta
}

mujiransismiharjo@gmail.com

\begin{abstract}
ABSTRAK
Latar Belakang: Hipertensi seringkali disebut sebagai pembunuh gelap (silent killer), dan masih menjadi masalah kesehatan pada kelompok lansia karena jika tidak terkendali akan berkembang dan menimbulkan komplikasi yang berbahaya. Angka kejadian stroke di UPT Puskesmas Jenawi tahun 2015 sebanyak 15 kasus dengan 8 kasus rawat inap. Pada tahun 2016 sebanyak 23 kasus dengan 11 kasus rawat inap dan 8 penderita stroke meninggal. Tujuan penelitian ini adalah untuk mengetahui hubungan antara tingkat pengetahuan tentang penyakit hipertensi dengan sikap pencegahan komplikasi hipertensi pada lansia peserta Prolanis UPT Puskesmas Jenawi Kabupaten Karanganyar.

Metode: Metode yang digunakan dalam penelitian ini adalah observasional analitik dengan pendekatan cross sectional study. Teknik pengambilan sampel dalam penelitian ini menggunakan Total sampling yaitu pengambilan sampel dari seluruh populasi yang ada yakni semua lansia penderita hipertensi peserta Prolanis UPT Puskesmas Jenawi Karanganyar Cara pengumpulan data dengan menggunakan kuesioner. Teknik analisis menggunakan uji Gamma.

Hasil: Berdasarkan hasil uji gamma didapatkan nilai $\mathrm{p}=0,000$, karena nilai $\mathrm{p}<0,05$ maka Ho ditolak sehingga Ha diterima.

Kesimpulan: Ada hubungan antara pengetahuan responden tentang penyakit hipertensi dengan sikap pencegahan komplikasi hipertensi pada lansia peserta prolanis pada UPT Puskesmas Jenawi Kabupaten Karanganyar. Dari uji yang sama diperoleh nilai $r=0,994$, karena nilai $r$ termasuk dalam rentang nilai $0,8-1,00$, maka dapat disimpulkan bahwa keduanya mempunyai hubungan yang sangat kuat.
\end{abstract}

Kata Kunci: Pengetahuan, Sikap, Hipertensi 


\begin{abstract}
Background: Hypertension is frequently recognized as a silent killer and still becomes a health problem encountered the elderly age group. When it is uncontrollable, it will develop and cause dangerous complications. The incidence rate of stroke at the the Technical Implementation Unit of Community Health Center of Jenawi in 2015 was 15 cases, and in 8 of which, the patients were hospitalized. In 2016, there were 23 cases. In 11 of which, the patients were hospitalized and in 8 of which, the patients passed away. The objective of this research was to investigate the correlation between the hypertension disease knowledge level and the attitudes in the prevention of hypertension complications of the elderly as the participants of Chronic Disease Management Program at the Technical Implementation Unit of Community Health Center of Jenawi, Karanganyar Regency.

Method: This research used the observational analytical research method with cross sectional study approach. Total sampling technique was used to determine its samples. The data of the research were analyzed through questionnaire and were then analyzed by using the Gamma's Test.

Results: The result of the Gamma's Test shows that the p-value was 0.000 which was less than 0.05 , meaning that $H_{o}$ was unverified but $H_{a}$ was verified.

Conclusion: Thus, the knowledge of hypertension disease had a correlation with the attitudes in the prevention of hypertesion complications of the elderlies as the participants of Chronic Disease Management Program at the Technical Implementation Unit of Community Health Center of Jenawi, Karanganyar Regency. The result of the test also shows that the r-value was 0.994, which was in the range of $0.8-1.00$, meaning that the two variables had a strong correlation.
\end{abstract}

Keywords: Knowledge, attitudes, hypertension

\section{PENDAHULUAN}

Hipertensi seringkali disebut sebagai pembunuh gelap (silent killer), karena termasuk penyakit yang mematikan, tanpa disertai dengan gejala-gejalanya lebih dahulu sebagai peringatan bagi korbannya. Kalaupun muncul, gejala tersebut seringkali dianggap gangguan biasa, sehingga korbannya terlambat menyadari akan datangnya penyakit ${ }^{[1]}$. Pencegahan komplikasi penyakit hipertensi harus dilakukan oleh penderita hipertensi untuk memperoleh kualitas hidup yang baik. Untuk mendapatkan kualitas hidup yang baik bagi penderita hiprtensi, perlu mengetahui beberapa hal berkaitan dengan penyakit hipertensi, terutama komplikasi yang mungkin bisa terjadi ${ }^{[1]}$.
Taxonomi Bloom membagi perilaku manusia menjadi tiga domain yakni kognitif, afektif, dan psikomotor. Pengetahuan mengenai penyakit hipertensi serta kemungkinan komplikasi yang bisa terjadi sangatlah penting bagi penderita hipertensi sebagai landasan dan motivasi untuk melakukan upaya pencegahan ${ }^{[2]}$. Hasil studi pendahuluan diperoleh data bahwa tingkat pengetahuan masyarakat di wilayah UPT Puskesmas Jenawi secara umum, yang ditunjukkan dengan kepemilikan ijazah pendidikan formal menunjukkan bahwa $66.91 \%$ berpendidikan Sekolah Dasar, 15.34\% tamat Sekolah Lanjutan Tingkat Pertama, $7.2 \%$ tamat Sekolah Lanjutan Tingkat Atas dan $1.35 \%$ tamat Perguruan Tinggi ${ }^{[3]}$. Dari hasil pendataan Perilaku Hidup Bersih dan Sehat (PHBS) tatanan 
rumah tangga diperoleh hasil $68 \%$ penduduk aktif mengkonsumsi tembakau (merokok) dan $15 \%$ penduduk aktif mengkonsumsi minuman keras (alkohol) ${ }^{[6]}$. Dari hasil studi pendahuluan juga didapatkan hasil bahwa sikap penderita hipertensi peserta Prolanis di UPT Puskesmas Jenawi masih kurang yaitu masih enggan untuk melakukan olah raga atau aktifitas fisik yang teratur, tidak mamatuhi diet yang teratur dan ada sebagian yang masih merokok walaupun tidak sesering dulu ${ }^{[6]}$. Tujuan penelitian ini adalah menganalisis hubungan antara tingkat pengetahuan tentang penyakit hipertensi dengan sikap pencegahan komplikasi hipertensi pada lansia peserta Prolanis UPT Puskesmas Jenawi Kabupaten Karanganyar.

\section{SUBJEK DAN METODE}

Metode yang digunakan dalam penelitian ini adalah observasional analitik dengan pendekatan cross sectional study ${ }^{[4]}$. Teknik pengambilan sampel dalam penelitian ini menggunakan Total sampling yaitu pengambilan sampel dari seluruh populasi ${ }^{[51}$ yang $\mathrm{ada}^{[2]}$. Besar sampel dalam penelitian ini adalah 55 orang $^{[6]}$ yang masuk kriteria inklusi. Penelitian dilakukan pada bulan Juni - Desember 2017 di UPT Puskesmas Jenawi Karanganyar. Instrumen dalam penelitian ini berupa lembar kuesioner ${ }^{[4]}$ tertutup untuk pengukuran tingkat pengetahuan tentang penyakit hipertensi dan sikap responden dalam melakukan pencegahan kompikasi hipertensi. Uji validitas dan reliabilitas dilaksanakan pada tanggal 17 Nopember 2017 di UPT Puskesmas Mojogedang II Karanganyar, dengan alasan bahwa lokasi uji validitas dan reliabilitas mempunyai karakteristik responden yang hampir sama dengan lokasi penelitian ${ }^{[4][7]}$. Analisa data dalam penelitian ini menggunakan Uji Gamma dengan taraf kemaknaan $5 \%[5]$.

\begin{tabular}{ccc}
\hline \multicolumn{3}{c}{ HASIL DAN PEMBAHASAN } \\
\hline $\begin{array}{c}\text { Tabel 1. Karakteristik } \\
\text { berdasarkan umur }\end{array}$ & responden \\
\hline Umur & $\mathrm{f}$ & $\%$ \\
$45-55$ tahun & 10 & 18.2 \\
$56-65$ tahun & 13 & 23.6 \\
$>65$ tahun & 32 & 58.2 \\
\hline Total & 55 & 100
\end{tabular}

Sumber: Data Primer (2017)

Berdasarkan hasil penelitian dapat diketahui bahwa sebagian besar responden dalam rentang usia lebih dari 65 tahun yaitu sebanyak 32 responden (58.2\%), sedangkan responden dengan rentang usia $56-65$ tahun sebanyak 13 responden $(23.6 \%)$ dan yang berada di rentang usia 46 - 55 tahun sebanyak 10 responden (18.2\%). Usia adalah umur individu yang terhitung mulai saat dilahirkan sampai berulang tahun. Semakin cukup umur tingkat kematangan dan kekuatan seseorang akan lebih matang dalam berfikir dan bekerja, dari segi kepercayaan masyarakat seseorang yang dewasa dipercaya dari orang yang belum tinggi kedewasaannya ${ }^{[8]}$. Hal ini sesuai dengan penelitian yang pernah dilakukan Istianah (2013) bahwa terdapat hubungan yang bermakna antara usia dengan pengetahuan ibu hamil tentang pemeriksaan antenatal care (ANC) ${ }^{[9]}$. Fibriana (2012) juga melakukan penelitian dengan hasil bahwa terdapat hubungan yang bermakna antara usia dengan tingkat pengetahuan remaja tentang dampak pernikahan dini ${ }^{[10]}$.

Proses penuaan akan berdampak pada berbagai aspek kehidupan, baik sosial, ekonomi maupun kesehatan. Ditinjau dari aspek kesehatan dengan semakin bertambahnya usia maka lansia lebih rentan terhadap berbagai keluhan fisik, baik karena faktor alamiah maupun penyakit ${ }^{[11]}$.

Tabel 2. Karakteristik responden berdasarkan jenis kelamin $(\mathrm{N}=55)$

\begin{tabular}{lcc}
\hline Jenis kelamin & $\mathrm{f}$ & $\%$ \\
\hline Laki - laki & 23 & 41,8 \\
Perampuan & 32 & 58,2 \\
\hline Total & 55 & 100 \\
\hline
\end{tabular}

Sumber: Data Primer (2017) 
Berdasarkan hasil penelitian dapat diketahui bahwa sebagian besar responden berjenis kelamin perempuan yaitu sebanyak 32 responden (58.2\%), sedangkan yang berjenis kelamin laki-laki sebanyak 23 responden $(41.8 \%)$. Hasil penelitian ini sesuai dengan kondisi proporsi jumlah lansia usia> 60 tahun di Indonesia bahwa jumlah lansia perempuan (11.4450.827 jiwa) lebih banyak jika dibanding lansia laki - laki (10.234.499 jiwa). Hal ini disebabkan karena usia harapan hidup perempuan lebih tinggi dari pada laki - laki ${ }^{[12]}$.

Tabel 3. Karakteristik responden berdasarkan pendidikan $(\mathrm{N}=55)$

\begin{tabular}{|c|c|c|}
\hline Pendidikan & $\mathrm{f}$ & $\%$ \\
\hline SD & 24 & 43.6 \\
\hline SLTP & 6 & 10.9 \\
\hline SLTA & 15 & 27.3 \\
\hline Perguruan Tinggi & 10 & 18.2 \\
\hline Total & 55 & 100 \\
\hline
\end{tabular}

Sumber: Data Primer (2017)

Berdasarkan hasil penelitian mayoritas responden dengan tingkat pendidikan Sekolah Dasar (SD) yaitu sebanyak 24 responden (43.6\%), sedangkan yang berpendidikan SLTP sebanyak 6 responden (10.9\%), SLTA sebanyak 15 responden (27.3\%) dan Perguruan Tinggi sebanyak 10 responden (18.2\%). Pendidikan adalah bimbingan yang diberikan seseorang terhadap perkembangan orang lain menuju ke arah cita-cita tertentu yang menentukan manusia untuk berbuat untuk mencapai keselamatan dan kebahagiaan. Pendidikan diperlukan untuk mendapatkan informasi yang akhirnya dapat mempengaruhi seseorang. Pada umumnya makin tinggi pendidikan seseorang makin mudah menerima informasi ${ }^{[8]}$. Dalam penelitian ini diperoleh gambaran tingkat pendidikan responden dalam katagori baik yaitu tingkat pendidikan SLTA dan perguruan tinggi sejumlah 25 responden $(45.5 \%)$. Hal ini sesuai dengan tingkat pengetahuan responden sebesar $50.9 \%$ dalam katagori baik. Hal ini sesuai dengan penelitian sebelum- nya yang dilakukan oleh Istianah (2010) bahwa terdapat hubungan yang bermakna antara tingkat pendidikan dengan pengetahuan ibu tentang miliariasis pada bayi ${ }^{[9]}$. Hasil Riskesdas (2013), dalam hal pendidikan, semakin tinggi pendidikan maka semakin besar tingkat pengetahuannya ${ }^{[14]}$. Karakteristik responden berdasarkan pekerjaan yaitu PNS/TNI/POLRI, pegawai swasta, petani, wiraswasta dan pensiunan dapat dilihat pada tabel 4.

Tabel 4. Karakteristik responden berdasarkan pekerjaan $(\mathrm{N}=55)$

\begin{tabular}{lcc}
\multicolumn{1}{c}{ Pekerjaan } & $\mathrm{f}$ & $\%$ \\
\hline PNS/TNI/POLRI & 2 & 3.6 \\
Pegawai Swasta & 3 & 5.5 \\
Petani & 24 & 43.6 \\
Wiraswasta & 3 & 5.5 \\
Pensiunan & 23 & 41.8 \\
& & \\
\hline \multicolumn{1}{c}{ Total } & 55 & 100 \\
\hline
\end{tabular}

Sumber: Data Primer (2017)

Hasil penelitian menunjukkan bahwa mayoritas pekerjaan responden sebagai petani yaitu sebanyak 24 responden (43.6\%), sedangkan PNS/TNI/POLRI sebanyak 2 responden (3.6\%), sebagai pegawai swasta sebanyak 3 responden $(5.5 \%)$, sebagai wiraswasta sebanyak 3 responden $(5.5 \%)$ dan sebagai pensiunan sebanyak 23 responden $(41.8 \%)$. Pekerjaan adalah kegiatan yang harus dilakukan terutama untuk menunjang kehidupannya dan kehidupan keluarga ${ }^{[8]}$. Hasil penelitian ini sesuai dengan kondisi di wilayah kerja UPT Puskesmas Jenawi Karanganyar merupakan daerah pegunungan dengan komposisi jumlah penduduk dengan mata pencaharian sebagai petani cukup tinggi, yaitu $68.9 \%{ }^{[6]}$. Karakteristik penduduk di pedesaan diketahui bahwa semua penduduk selagi masih mampu bekerja akan terus bekerja tidak terpangaruh usia karena bekerja untuk memenuhi kebutuhan hidupnya.

Tabel 5. Karakteristik responden mengenai informasi penyakit hipertensi $(\mathrm{N}=55)$ 


\begin{tabular}{lcc}
\hline $\begin{array}{l}\text { Informasi Penyakit } \\
\text { Hipertensi }\end{array}$ & $\mathrm{f}$ & $\%$ \\
\hline Keluarga & 4 & 7.3 \\
Pelayanan & 51 & 92.7 \\
Kesehatan & 0 & 0 \\
Media & 0 & 0 \\
Lain-lain & 0 & 0 \\
Tidak pernah & 0 & 0 \\
\hline Total & 55 & 100
\end{tabular}

Sumber: Data Primer (2017)

Hasil penelitian menunjukkan bahwa sebagian besar responden mendapatkan informasi penyakit hipertensi dari pelayanan kesehatan yaitu sebanyak 51 responden $(92.7 \%)$, sedangkan dari keluarga 4 responden $(7.3 \%)$. Seseorang yang mempunyai sumber informasi yang lebih banyak akan mempunyai pengetahuan yang lebih luas ${ }^{[8]}$.

Sebagian besar responden $(92.7 \%)$ menyatakan memperoleh informasi tentang penyakit hipertensi dari pelayanan kesehatan. Hal ini sesuai dengan hasil studi pendahuluan yang dilakukan penulis di lokasi penelitian bahwa kegiatan pelayanan kesehatan yang diakukan UPT Puskesmas Jenawi Kabupaten Karanganyar kepada masyarakat khususnya kepada para lansia penderita hipertensi adalah Posyandu Lansia, Posbindu dan Prolanis. Posyandu Lansia dilaksanakan setiap bulan sekali di setiap desa di seluruh wilayah kerja puskesmas dengan kegiatan berupa penyuluhan kesehatan, pemeriksaan kesehatan, pengukuran berat badan, pengukuran tinggi badan, pengukuran tekanan darah dan pengobatan. Posbindu dilaksanakan sebulan sekali di seluruh wilayah kerja puskesmas dengan kegiatan penyuluhan kesehatan, pengukuran berat badan, pengukuran tinggi badan, pengukuran tekanan darah, pengukuran lingkar perut dan pengukuran indeks masa tubuh (IMS). Prolanis dilaksanakan setiap bulan dua kali dilaksanakan di puskesmas dengan kegiatan penyuluhan kesehatan, senam lansia, pengukuran tekanan darah, pemeriksaan laboratorium dan pengobatan. Prolanis yang diikuti oleh responden sudah berlangsung cukup lama, yaitu sejak tahun 2012 dengan kegiatan rutin berupa penyuluhan kesehatan tentang penyakit hipertensi, pengukuran tekanan darah serta pengobatan, [6]. Hasil penelitian ini juga sesuai dengan tingkat pengetahuan resonden yang baik mengenai penyakit hipertensi ( $50,9 \%)$. Tingkat pengetahuan responden yaitu baik, cukup dan kurang dapat dilihat pada tabel 6.

Tabel 6. Tingkat Pengetahuan Responden tentang penyakit hipertensi $(\mathrm{N}=55)$

\begin{tabular}{lcc}
\hline \multicolumn{1}{c}{$\begin{array}{c}\text { Tingkat } \\
\text { Pengetahuan }\end{array}$} & $\mathrm{f}$ & $\%$ \\
\hline Baik & 28 & 50.9 \\
Cukup & 24 & 43.6 \\
Kurang & 3 & 5.5 \\
\hline \multicolumn{1}{c}{ Total } & 55 & 100 \\
\hline
\end{tabular}

Sumber: Data Primer (2017)

Hasil penelitian tingkat pengetahuan responden tentang penyakit hipertensi didapatkan tingkat pengetahuan baik sebanyak 28 responden (50.9\%), tingkat pengetahuan cukup sebanyak 24 responden (43.6\%) dan tingkat pengetahuan kurang sebanyak 3 responden $(5.5 \%)$.

Menurut Notoatmodjo (2012), pengetahuan adalah hasil dari tahu dan ini terjadi setelah orang melakukan penginderaan terhadap suatu objek tertentu ${ }^{[2]}$. Penginderaan terjadi melalui pancaindera manusia, yakni indera penglihatan, pendengaran, penciuman, rasa, dan raba. Sebagian pengetahuan manusia diperoleh melalui mata dan telinga. Sedangkan menurut Astinah (2013), pengetahuan adalah pembentukan pemikiran assosiatif yang menghubungkan atau menjalin sebuah pemikiran dengan kenyataan atau pikiran lain berdasarkan pengalaman yang berulangulang tanpa pemahaman mengenai kausalitas (sebab-akibat) yang universal ${ }^{[13]}$.

Tingkat pengetahuan responden dalam katagori baik (50.9\%) dimungkinkan karena pendidikan responden cukup baik, tingkat pendidikan SLTA dan yang lebih 
tinggi sejumlah (45.5\%). Penelitian yang dilakukan oleh Istianah (2010) didapatkan hasil bahwa ada hubungan yang bermakna antara tingkat pendidikan dengan pengetahuan ${ }^{[9]}$. Hal ini sesuai dengan hasil studi pendahuluan yang dilakukan peneliti bahwa kegiatan pelayanan kesehatan yang di- lakukan oleh tenaga kesehatan UPT Puskesmas Jenawi untuk meningkatkan pengetahuan kepada responden cukup bervariasi dan intens yaitu dalam kegiatan Posyandu Lansia, Posbindu dan Prolanis ${ }^{[6]}$. Hasil analisis hubungan antara pengetahuan dengan sikap terdapat pada tabel 7 .

Tabel 7. Hubungan antara pengetahuan dengan sikap ( $\mathrm{N}=55$ )

\begin{tabular}{ccccc}
\hline & Value & $\begin{array}{c}\text { Asymp. Std. } \\
\text { Error }^{\mathrm{a}}\end{array}$ & Approx. T & $\begin{array}{c}\text { Approx. } \\
\text { Sig. }\end{array}$ \\
\hline $\begin{array}{l}\text { Ordinal by Gamma } \\
\begin{array}{l}\text { Ordinal } \\
\text { N of Valid Cases }\end{array}\end{array}$ & .994 & .007 & 16.170 & .000 \\
\hline
\end{tabular}

Hasil Riskesdas (2013), dalam hal pendidikan, semakin tinggi pendidikan maka semakin besar persentase pengetahuannya ${ }^{[11]}$.

Tabel 8. Sikap responden dalam pencegahan komplikasi hipertensi $(\mathrm{N}=$ 55)

\begin{tabular}{ccc}
\hline Sikap & $\mathrm{f}$ & $\%$ \\
\hline Baik & 47 & 85.5 \\
Kurang & 8 & 14.5 \\
\hline Total & 55 & 100 \\
\hline
\end{tabular}

Sumber: Data Primer (2017)

Hasil penelitian sikap responden dalam pencegahan komplikasi hipertensi didapatkan sebagian besar sikap responden baik sebanyak 47 responden $(85.5 \%)$ dan respondnen dengan sikap kurang sebanyak 8 responden (14.5\%). Menurut Notoadmodjo (2012) sikap merupakan reaksi atau respon seseorang yang masih tertutup terhadap suatu stimulus atau objek. Sikap itu tidak dapat langsung dilihat, tetapi hanya bisa ditafsirkan terlebih dahulu. Dalam kehidupan sehari-hari adalah merupakan reaksi yang bersifat emosional terhadap stimulus sosial ${ }^{[2]}$. Azwar (2013) menyimpulkan bahwa faktor-faktor yang mempengaruhi pembentukan sikap adalah pengalaman pribadi, kebudayaan, orang lain yang dianggap penting, media massa, institusi atau lembaga pendidikan dan lembaga agama, serta faktor emosi dalam diri individu ${ }^{[14]}$.

Hasil penelitian menunjukkan bah- wa sebagian besar responden mempunyai sikap yang baik $(85.5 \%)$ dalam pencegahan komplikasi hipertensi. Hal ini sesuai dengan teori bahwa pembentukan sikap dipengaruhi oleh antara lain orang lain yang dianggap penting dan institusi ${ }^{[14]}$, dalam hal ini orang lain yang dianggap penting tersebut adalah petugas kesehatan serta institusinya adalah UPT Puskesmas Jenawi. Informasi tentang penyakit hipertensi yang dimiliki responden sebagian besar dari pelayanan kesehatan (92.7\%).

Analisis bivariat dilakukan untuk mengetahui hubungan antara tingkat pengetahuan tentang hipertensi dengan sikap pencegahan komplikasi hipertensi pada lansia peserta Prolanis UPT Puskesmas Jenawi Kabupaten Karanganyar. Berdasarkan hasil uji gamma didapatkan nilai $\mathrm{p}$ $=0.000$ dan nilai $\mathrm{p}<0.05$, berarti Ho ditolak dan Ha diterima. Kesimpulan : Ada hubungan antara tingkat pengetahuan responden tentang penyakit hipertensi dengan sikap pencegahan komplikasi hipertensi pada lansia peserta Prolanis pada UPT Puskesmas Jenawi Kabupaten Karanganyar. Ditinjau dari aspek tingkat keeratan hubungan didapatkan hasil nilai $r$ $=0.994$, artinya nilai $\mathrm{r}$ termasuk dalan range nilai $0.8-1.00$, berarti keduanya mempunyai hubungan yang sangat kuat.

Hasil penelitian yang dilakukan oleh Pratiwi (2014) memberikan hasil bahwa ada hubungan yang bermakna antara ting- 
kat pengetahuan dengan sikap ibu dalam pemberian imunisasi dasar pada bayi ${ }^{[15]}$. Juga penelitian yang dilakukan oleh Ainiyah (2015), menyatakan bahwa ada hubungan yang signifikan antara tingkat pengetahuan ibu tentang ISPA dengan sikap ibu dalam pencegahan penularan ISPA pada bayi usia 0 s.d 12 bulan $^{[16]}$. Penelitian lain yang dilakukan oleh Agustina (2016) yang menyatakan bahwa ada hubungan yang bermakna antara pengetahuan dan sikap perawat dalam pelaksanaan ronde keperawatan $^{[17]}$.

Tingkat keeratan hubungan menunjukkan hubungan sangat erat, artinya bahwa semakin tinggi tingkat pengetahuan responden tentang penyakit hipertensi semakin baik sikap responden dalam pencegahan komplikasi hipertensi. Hasil penelitian ini sangat bermanfaat bagi tenaga kesehatan khususnya perawat di UPT Puskesmas Jenawi Kabupaten Karanganyar untuk senantiasa memberikan pelayanan kesehatan dalam rangka meningkatkan pengetahuan para lansia di wilayah kerja puskesmas, dengan harapan tingkat komplikasi hipertensi dapat ditekan dengan adanya sikap yang baik dari para penderita hipertensi dalam upaya melakukan upaya pencegahan.

\section{KESIMPULAN}

Hasil penelitian tentang hubungan tingkat pengetahuan tentang penyakit hipertensi dengan sikap dalam pencegahan komplikasi hipertensi pada lansia peserta Prolanis di UPT Puskesmas Jenawi Kabupaten Karanganyar dapat disimpulkan sebagai berikut:

1. Gambaran karakteristik responden diketahui bahwa sebagian besar berusia lebih dari 60 tahun, berjenis kelamin perempuan, berpendidikan Sekolah Dasar, bekerja sebagai petani dan mendapatkan informasi tentang penyakit hipertensi dari pelayanan kesehatan.

2. Tingkat pengetahuan responden tentang penyakit hipertensi sebagian besar dalam katagori pengetahuan baik sebanyak 28 responden $(50.9 \%)$.

3. Sebagian besar sikap responden dalam kategori baik yaitu sebanyak 47 responden $(85.5 \%)$

4. Ada hubungan yang bermakna antara tingkat pengetahuan responden tentang penyakit hipertensi dengan sikap pencegahan komplikasi hipertensi pada lansia peserta Prolanis pada UPT Puskesmas Jenawi Kabupaten Karanganyar.

\section{SARAN}

1. Lansia

Diharapkan seluruh lansia penderita hipertensi peserta Prolanis lebih menekuni dan mengikuti kegiatan dengan baik supaya mempunyai sikap yang baik dalam mencegah komplikasi dari penyakit hipertensi yang dideritanya.

2. Tenaga kesehatan

Tetap mempertahankan kegiatan Prolanis dengan penyuluhan kesehatan untuk meningkatkan pengetahuan peserta supaya mempunyai sikap yang baik dalam mencegah komplikasi penyakit kronis yang dideritanya.

3. Puskesmas

Mengembangkan kegiatan Prolanis untuk memfasilitasi lansia yang menderita penyakit kronis untuk mendapatkan informasi kesehatan berkaitan dengan penyakitnya.

4. DKK Karangayar

Diharapkan bisa menjembatani komunikasi dengan BPJS untuk penyelenggaraan Prolanis yang lebih baik dan merata kepada semua lansia yang membutuhkan

5. Peneliti selanjutnya

Diharapkan dapat mengembangkan lebih lanjut penelitan yang sejenis dengan meneliti faktor-faktor yang mempengaruhi tingkat pengetahuan, sikap dan perilaku lansia dalam pencegahan komplikasi hipertensi. 


\section{DAFTAR PUSTAKA}

1. Sustrani. Hipertensi. Jakarta: Gramedia Pustaka Utama; 2009.

2. Notoadmodjo S. Metodologi Penelitian Kesehatan. Jakarta: Reneka Cipta; 2011

3. Notoadmodjo S. Promosi Kesehatan dan Ilmu Perilaku. Jakarta: Reneka Cipta; 2012.

4. Arikunto S. Prosedur Penelitian Suatu Pendekatan Praktik. Jakarta: Rineka Cipta; 2010.

5. Sugiyono. Statistika Untuk Penelitian. Bandung: Alfabeta; 2010.

6. Puskesmas Jenawi. Laporan Pengumpulan Data Cakupan Program Pengobatan Puskesmas Kecamatan Jenawi Tahun 2017. Tidak dipublikasikan; 2017.

7. Riwidigdo H. Statistik Kesehatan. Yogyakarta: Mitra Cendikia Press; 2013.

8. Wawan A., Dewi M. Teori dan Pengukuran Pengetahuan, Sikap, dan Perilaku. Yogyakarta: Nuha Medika; 2010.

9. Istianah. Hubungan Antara Usia Dengan Pengetahuan Ibu Hamil Tentang Pemeriksaan Antenatal Care di BPS Ny. Siti Khinainah, AMd.Keb Desa Popoh Kecamatan Wonoayu Kabupaten Sidoarjo, Naskah Publikasi; 2013.

10. Fibriana FD. Hubungan Antara Usia Dengan Tingkat Pengetahuan Remaja Tentang DAmpak Pernikahan Usia Dini Di MA Nurul Islam Silo
Kabupaten Jember, Naskah Publikasi; 2012.

11. Kementrian Kesehatan RI. Pusat Data dan Informasi. Jakarta: Kemenkes RI; 2014.

12. Kementrian Kesehatan RI. Pusat Data dan Informasi. Jakarta: Kemenkes RI; 2015.

13. Astinah. Faktor-Faktor Yang Mempengaruhi Kepatuhan Ibu Pada Pemberian Imunisasi Dasar Di Posyandu Teratai Di Wilayah Kerja Puskesmas Tamamaung Makasar. Elibrary STIKES Nani Hasanuddin Makasar. 2013;2(6).

14. Azwar S. Sikap Manusia Teori dan Pengukurannya. Yogyakarta : Pustaka Pelajar Offset; 2013.

15. Pratiwi NP. Hubungan Antara Tingkat Pengetahuan Ibu Dengan Sikap dan Perilaku Ibu Terhadap Pemberian Imunisasi Dasar Pada Bayi di Desa Penatih Dangin Puri, ejurnal Medika. 2017;6(10).

16. Ainiyah N. Hubungan Tingkat Pengetahuan Ibu Tentang ISPA dengan Sikap Ibu Tentang Pencegahan Penularan ISPA Pada Bayi Usia 0-12 Bulan di Puskesmas Pandaan, Jurnal Ilmiah Kesehatan. 2017;10(1).

17. Agustina V. Hubungan Tingkat Pengetahuan dengan Sikap Perawat dalam Pelaksanaan Ronde Keperawatan di Ruang Aster dan ICCU RSUP dr. Doris Sylvanus, Journal Dinamika Kesehatan. 2016;7(1). 